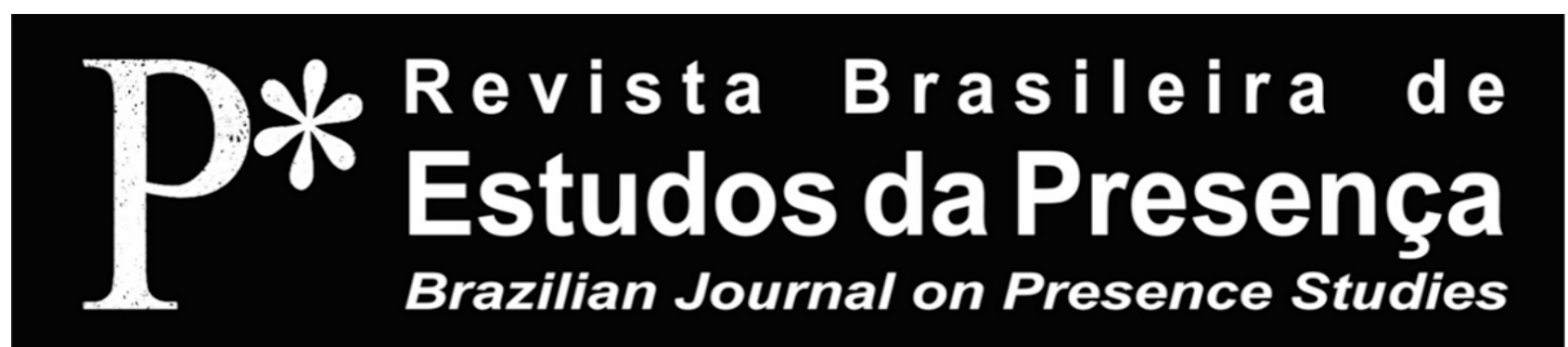

\title{
Dança, corpo e memória: as três temporadas do Original Ballet Russe no Rio de Janeiro
}

Beatriz Cerbino ${ }^{I}$

IUniversidade Federal Fluminense - UFF, Niterói/RJ, Brasil

\begin{abstract}
RESUMO - Dança, corpo e memória: as três temporadas do Original Ballet Russe no Rio de Janeiro - Este texto tem como objetivo apresentar algumas reflexóes entre os estudos da história, da memória e da dança. Parte-se do campo da História a fim de entender o papel da memória no processo de produçáo de conhecimento. Como estudo de caso, tomo as três temporadas do Original Ballet Russe no Rio de Janeiro, em 1942, 1944 e 1946, momentos em que a companhia foi apontada como exemplo para a construçáo de um balé nacional e demonstro como o discurso constituído na imprensa carioca em torno dessa presença elaborou essa articulação. Para tal, utilizo como fontes as críticas de Jaques Corseuil, lançando mão dos procedimentos metodológicos da história cultural.

Palavras-chave: Dança. História. Memória. Original Ballet Russe. Rio de Janeiro.
\end{abstract}

ABSTRACT - Dance, body and memory: the Original Ballet Russe and its three seasons in Rio de Janeiro - This text presents reflections on studies of history, memory and dance. I start from the field of History and my interest in understanding the role of memory in knowledge production processes. As a case study, I examine the three Original Ballet Russe seasons in the city of Rio de Janeiro, which took place in 1942, 1944 and 1946. During this period, the company was seen as exemplary in its contribution to the building of Brazilian national ballet. I demonstrate how the discourse employed by the local press fueled these ideas. Guided by the methodological procedures of cultural history, I use dance critic Jaques Corseuil's reviews as key sources.

Keywords: Dance. History. Memory. Original Ballet Russe. Rio de Janeiro.

RÉSUMÉ - Danse, corps et mémoire: les trois saisons de l'Original Ballet Russe à Rio de Janeiro - Cet texte vise à présenter quelques réflexions sur les études de l'histoire, de mémoire et de la danse. Nous partons du domain de l'Histoire pour comprendre le rôle de la mémoire dans le processus de production des connaissances. Comme étude de cas, je prends les trois saisons de l'Original Ballet Russe à Rio de Janeiro en 1942, 1944 et 1946 moments où la compagnie a été signaleé comme un example pour la construction d'un ballet national et je montre comment le discours constitué dans la presse de Rio élaboré cette articulation. Pour cela, j'utilise comme sources les critiques de Jaques Corseuil, en utilisant les procédés méthodologiques de l'histoire culturelle.

Mots-clés: Danse. Histoire. Mémoire. Original Ballet Russe. Rio de Janeiro. 


\section{Para começar}

Esse texto parte de alguns aspectos relacionadas à produçáo de conhecimento no campo da História e na sua relação com a dança cênica, a fim de observar as três temporadas realizadas pelo Original Ballet Russe no Rio de Janeiro, em 1942, 1944 e 1946, e apontar a percepção construída pela crítica especializada, em especial a partir dos textos do jornalista e crítico de dança Jaques Corseuil (1913 - 2000) sobre as passagens da companhia pela cidade.

Considerada um dos mais importantes grupos de dança da primeira metade do século XX, o Original Ballet Russe apresentou-se, desde seu início, como herdeiro direto do Ballets Russes de Diaghilev ${ }^{1}$, companhia dirigida pelo empresário russo Serge Dighilev $(1872$ - 1929) que existiu de 1909 a $1929^{2}$, tendo como referência a qualidade técnica de seus bailarinos e as produçôes cênicas apuradas e inovadoras, porém sem abrir máo da tradiçáo da técnica de balé3. A influência da companhia de Diaghilev, ao "[...] transformar o balé em uma arte moderna e vital” (Garafola, 1998, p. 7), com ênfase em coreografias, músicas, cenários e figurinos originais, fez-se perceber não apenas durante as duas décadas em que existiu, mas também nos anos seguintes ao seu fim, "[...] a influência da companhia foi enorme tanto no palco quanto fora dele" (Craine; Mackrell 2000, p. 47).

Em 1932, três anos após o desbande do Ballets Russes de Diaghilev, dois empresários, o russo Vassily Grigorievich Voskresensky (1888 - 1951), conhecido como Coronel Wassily de Basil, e o francês René Blum (1878 1942), tomaram para si a tarefa de continuar o trabalho de Diaghilev e fundaram os Ballets Russes de Monte Carlo. Sociedade rompida em 1936, quando De Basil acrescentou seu nome ao da companhia. Nesse mesmo ano, Blum fundou os Ballets de Monte Carlo, grupo que se transferiu para os Estados Unidos, em 1939, onde permaneceu até sua última temporada, em 1961-62 (Craine; Mackrel 2000, p. 44).

Após três mudanças de nome - Ballets Russes do Cel. W. de Basil, durante as temporadas de 1936 e 1937, Convent Garden Russian Ballet, em 1938, e Educational Ballet, Ltd., entre 1938 e 1939 - a companhia passou a se chamar definitivamente, a partir de 1939, Original Ballet Russe, que permaneceu até 1952, quando foi oficialmente desfeita (García-Marques, 1990, 
p. 15-17; Victorica, 1948, p. 255). É importante perceber que, apesar das mudanças envolvendo o nome do grupo, ele manteve o balé como técnica formadora de seus bailarinos e das coreografias que encenou. $\mathrm{Ou}$ seja, manteve a herança diaghileviana, da qual se percebia como legítimo sucessor, reafirmando a tradição do balé como aspecto central da construção de sua identidade.

Essa rápida genealogia do Original Ballet Russe se faz necessária para entender sua importância e inserção no cenário internacional da dança e como se posicionava, em termos artísticos-políticos, nos países em que se apresentava. Em entrevista à revista Ilustração Brasileira, De Basil salientou que o papel do grupo era, sobretudo, contribuir para o desenvolvimento do balé:

[...] a nossa companhia desperta o interesse pela dança e todos os países por onde passa terão seu bailado à base do Balé Russo. Pela curiosidade do público e da imprensa, pelo influxo resultante na poesia, na música e na pintura, ele inspira um ambiente para o florescimento da dança, do qual resulta a ideia de formação de um balé nacional (Corseuil, 1942, p. 28).

Essa fala importa, mesmo levando em conta o tom autoritário ali presente, pois dá pistas das complexas relaçóes instauradas entre dança, nesse caso especificamente o balé, e a ideia de nacional então vigente. Cabe ressaltar que não se tratava de qualquer balé: este deveria se desenvolver a partir de referenciais russos e guardar, ao mesmo tempo, elementos nacionais em sua constituição. Buscava-se assim, por um lado, um corpo que pudesse ser reconhecido a partir dos parâmetros técnicos do balé russo, segundo De Basil, e, por outro, uma produção cênica capaz de articular características entáo apontadas como definidoras de um bailado nacional - coreografias criadas a partir de temáticas brasileiras e da participação de artistas locais em sua criação, como músicos e artistas visuais, responsáveis pelo desenvolvimento de cenários e figurinos.

A busca pelo chamado bailado nacional se insere na ideologia do regime autoritário do Estado Novo (1937 - 1945) de Getúlio Vargas (1882 - 1954), que tinha como um de seus focos "[...] fortalecer o sentimento de identidade nacional, de brasilidade", por meio da "[...] valorização da cultura e da 
educação" (Pereira, 2003, p. 276), em uma estratégia de atuação de rígida política de vigilância e controle dos meios de comunicação, em especial rádio e imprensa ${ }^{4}$. Foi nesse contexto que De Basil apresentou seu Projeto para a organizaçâo do Teatro Nacional de Bailados, que acabou por náo ser implementado. Segundo ele, caberia a um grupo de artistas do balé tradicional, o que deve ser entendido como balé russo, especificamente sua companhia, a tarefa de organizar e efetivar o funcionamento "[...] uma instituição exemplar, que servirá sob o pretexto do ensino da dança, para a educação geral” (Pereira, 2003, p. 310). Apesar de não se ter o ano de sua formulaçáo, 1942 ou 1944, percebe-se a proximidade com as ideias defendidas pelo Estado Novo, como a relação estreita entre cultura, arte e educação, e sua utilização para propaganda do regime.

A imprensa, firmemente censurada pelo Departamento de Imprensa e Propaganda (DIP) do Estado Novo, assim como o rádio, teatro e cinema, também contribuiu para a efetivação do projeto estadonovista, tanto pela publicação de matérias a ele favoráveis, quanto de críticas de dança que corroboravam a perspectiva do nacionalismo a ser colocada em cena.

Algumas das relaçóes possíveis de serem estabelecidas entre os referenciais teóricos de história e de memória e a crítica de dança são importantes para entender como essa escrita, da crítica, pode ser utilizada no processo de coleta de informaçóes e de reflexão acerca do corpo que dança e da cena construída. Longe de serem entendidos como verdades absolutas, as críticas de dança são documentos que nos dão pistas do passado, no entrelaçamento de "[...] concepçôes estéticas formuladas por grupos ou indivíduos envolvidos na prática artística comentada às tensões e estratégias que compóem os discursos históricos" (Guarato 2019, p. 236). Textos, portanto, que devem ser percebidos como fontes que informam e situam os espetáculos, assim como a atuação de bailarinos e bailarinas, em um processo contínuo de construção da memória. É a partir dessa perspectiva que as temporadas do Original Ballet Russe, na cidade do Rio de Janeiro, e algumas críticas e textos publicados por Jaques Corseuil (1913 - 2000) sobre a companhia serão, aqui, tratados.

Um dos primeiros críticos a especializar-se em dança cênica na imprensa carioca $^{5}$, com uma profícua produção textual entre as décadas de 1940 e 
1960, Corseuil escreveu para diferentes veículos, jornais e revistas, como Brasil Musical, A Cena Muda, Cinearte, Correio da Manhã, Diário Carioca, Ilustração Brasileira e $O$ Globo. Entre matérias jornalísticas sobre companhias e críticas dos espetáculos, ele articulou importantes narrativas sobre a dança nos meios de comunicação, desempenhando papel fundamental no processo de formaçáo de público para essa arte, na defesa do que na época se entendia por bailado nacional, além de um eloquente discurso sobre a necessidade de investimentos na formaçáo de bailarinos brasileiros ${ }^{6}$ (Cerbino, 2011). Não à toa, Corseuil viria a fundar, junto ao artista visual Sansáo Castello Branco (1920 - 1956), o Ballet da Juventude, companhia que existiu por dez anos, entre 1946 e 1956, criada aos moldes do Original Ballet Russe ${ }^{7}$.

Manter a tradição do balé, mas sem deixar de lado o moderno em suas produçôes, era o lema do Original Ballet Russe, discurso assimilado por Jaques Corseuil para as produçóes feitas pelo entáo Corpo de Baile do Theatro Municipal, hoje Ballet do Theatro Municipal. Criado em 1936, pela mestra, bailarina e coreógrafa Maria Olenewa (1896 - 1965), russa naturalizada brasileira, que, nove anos antes, em 1927, já havia constituído a Escola de Baile do Theatro Municipal, primeira escola oficial de dança no Brasil (Pavlova, 2001, p.33) o Corpo de Baile fez sua primeira temporada oficial em 1939. Como aponta Roberto Pereira, tratava-se de um momento especial: o balé feito em corpos brasileiros se deparava com a tarefa de buscar "[...] possíveis respostas para um nacionalismo que ia ganhando outros tons, principalmente na ideologia varguista que se instaurava" (Pereira, 2003, p. 138). As críticas de dança e as matérias jornalísticas produzidas por Jaques Corseuil, sobretudo as publicadas ao longo da década de 1940, apontam esse processo e sáo importantes fontes para acompanhar como essa busca indicada por Pereira era então tratada.

Aspecto central do fazer histórico, o trabalho com as fontes é fundamental para que o historiador realize sua investigaçáo. Trabalho que passa, necessariamente, pela escolha e como as fontes são interrogadas. Materiais e imateriais, assim como seus vestígios, esses documentos históricos são "[...] tudo do que o homem diz ou escreve, tudo que fabrica, tudo que toca e pode informar sobre ele" (Bloch, 2001, p. 79). Nesse sentido, a produção em dança, 
tudo que envolve seu processo de criação, como coreografia, o corpo que dança, cenário, figurino e trilha sonora, e sobre a dança, como críticas e matérias na mídia, podem ser percebidas como fontes.

$\mathrm{O}$ acervo de Jaques Corseuil, trabalhado neste texto, apresenta documentos valiosos, entre textos escritos, programas e imagens, que informam sobre as temporadas do Original Ballet Russe na cidade do Rio de Janeiro. Como procedimento metodológico, tais fontes foram tratadas como registros capazes de fornecer informaçóes sobre o passado, que permitem acessar os diferentes tempos e escolhas ali contidas. A história cultural, assim como os estudos da memória, foram os referenciais teóricos utilizados para a realização dessa investigação.

\section{História, memória e crítica de dança}

Para conhecer a crítica, no sentido do texto produzido, quais ideias ela defende e como as organiza, é necessário perceber as questóes que permeiam as escolhas ali presentes, ou seja, o contexto cultural, político, econômico, artístico e social em que foram realizadas. Longe de uma busca totalizante, a fim de conhecer o passado "[...] como ele de fato foi" (Guinzburg, 2007, p. 10), trata-se de apontar vestígios e pistas, assim como as tensóes, das diferentes passagens da companhia pelo Theatro Municipal do Rio de Janeiro, em que foram apresentados distintos programas, constituídos de obras coreográficas diversificadas (Chaves, 1971, p. 284, 286, 287-288).

A análise desenvolvida, a partir das categorias de representação, prática e apropriação, proveniente da história cultural (Burke 2005, Chartier 2002a), é central para a reflexão das relaçóes engendradas entre dança, corpo e o contexto social. Parte-se da perspectiva de história cultural como o estudo dos processos, das representaçôes, das classificaçôes e das exclusões que constituem as configurações sociais e conceituais próprias de um tempo ou de um espaço, entendendo-se os aspectos culturais em função de duas concepções básicas: as práticas e as representaçóes. As estruturas do mundo social não são, portanto, dados objetivos, mas produzidas historicamente por práticas articuladas que, por sua vez, constroem e deixam suas marcas em figuras e representações, isto é, nas produçóes culturais realizadas (Chartier, 2002a, p. 4- 
28). Logo, os documentos que descrevem ações simbólicas do passado não são textos neutros, inocentes e transparentes, mas escritos com diferentes intençôes e estratégias. As condiçóes e os processos que operam na construção de sentidos, além de indicar a pluralidade dos usos e dos modos de emprego das questóes intelectuais e das formas culturais, apontam importantes aspectos do pensamento do historiador francês Roger Chartier: que "[...] tais operaçôes são encarnadas, ao mesmo tempo em que são construídas na descontinuidade das trajetórias históricas" (2002a, p. 27).

Ao concentrar a ênfase de sua análise na pluralidade dos modos de usar, de compreender, de experimentar e de vivenciar as obras e as normas presentes e em circulação na sociedade, Chartier se afasta de um recorte social simplificador que estabelece previamente a distribuição de objetos e desloca o foco para os usos e as distinçóes aí geradas. Trata-se de uma perspectiva que não é neutra, ao contrário, aponta para o fato das práticas culturais serem, sistematicamente, objeto de lutas sociais que as classificam, consagrando-as ou desqualificando-as. Nesse sentido, há uma relação intrínseca entre práticas e representaçôes, a partir da qual é possível elaborar uma interpretação do social em que as ideias e as práticas aí surgidas não estão descoladas de suas trajetórias históricas, ou muito menos desencarnadas. A operação de produção de sentido ocorre, portanto, "[...] por meio da apropriação realizada por grupos ou por indivíduos" (Chartier 1995, p. 184). Assim, na trama das relações constituídas entre produçóes culturais de diferentes grupos sociais nos espetáculos de dança do Rio de Janeiro, é possível perceber como o balé se apropriou de informaçóes e encarnou, em seu fazer, modos distintos de se movimentar, construindo uma rede de escrituras evidenciada no corpo.

Percepção que é central quando se trabalha com dança, pois se trata de perceber que as práticas e as apropriaçóes se materializam no próprio corpo, como representaçôes encarnadas, ou seja, a construção de sentido se dá também em movimentos dançados. Práticas perceptíveis na maneira de se movimentar dos bailarinos, articuladas em um contexto espacial, temporal, cultural, político e socioeconômico e fundamentais para o entendimento da dança cênica, aqui a ser tratada. As críticas e os textos de Jaques Corseuil, tratados a partir de uma perspectiva metodológica que vislumbra tais entrelaçamentos, 
são ricos mananciais para a compreensão das escolhas colocadas em movimento pelos corpos dos bailarinos e bailarinas do Original Ballet Russe.

Em um pequeno livro, publicado em 2006, Uma história do corpo na Idade Média, os historiadores Jacques Le Goff e Nicolas Truong fazem uma instigante reflexáo sobre o corpo na Idade Média, indicando como a história, em seu sentido mais tradicional, colocava-se de maneira desencarnada, ou seja, alijando o corpo e seus fazeres de boa parte da investigação acadêmica, a náo ser por exceçóes, como os trabalhos desenvolvidos por Michel Foucault, Norbert Elias, Marc Bloch, Michel de Certeau, Mikhail Bakhtin, George Duby e Paul Veine ${ }^{8}$. Mesmo que o recorte temporal seja a Idade Média, as reflexóes realizadas pelos autores, assim como a metodologia utilizada, são importantes para a sistematização dos estudos do corpo, a partir das questóes: como deve ser estudado e contextualizado? Como o corpo foi pensado e visualizado? O que foi o corpo para as diferentes sociedades ao longo do tempo?

Le Goff e Truong partem para a tarefa de utilizar o corpo como objeto de pesquisa, afirmando que "[...] o corpo tem uma história, o corpo é a nossa história”. Nesse livro, assim como na importante publicação em três volumes História do corpo (Corbin; Courtine; Vigarello, 2008), fica claro que o estudo do corpo é indispensável para a compreensão do mundo em que vivemos e como atuamos, não apenas pelo espaço que conquistou nas últimas décadas como objeto de estudo, mas também como fonte viável de investigação da construção das diferentes dinâmicas e dos sentidos realizados socialmente. De maneira eloquente, Le Goff e Truong apontam que,

A história do corpo oferece ao historiador e ao interessado em história uma vantagem, um interesse suplementar. $\mathrm{O}$ corpo ilustra e alimenta uma história lenta. A essa história lenta, que é, em profundidade, a das idéias, das mentalidades, das instituiçóes e mesmo a das técnicas e das economias, esse interesse dá um corpo, o corpo (2006, p. 173).

Refletir sobre o corpo e sua história é, portanto, chave para a compreensão da sociedade e as transformaçóes vivenciadas ao longo dos séculos. Por outro lado, os estudos da memória são igualmente importantes para entender que não se trata de resgatar fatos e acontecimentos deixados para trás, mas que o processo de produçáo da memória se faz a partir da perspectiva do 
presente, com os questionamentos construídos no aqui e agora. Memória e história não são sinônimos, conforme aponta o historiador francês Pierre Nora (1993), porém, estão longe do antagonismo. Operaçóes narrativas distintas, cada uma com suas particularidades, mais interessante é percebê-las como construções, sempre problemáticas, pois incompletas. A memória é, por natureza, e ao mesmo tempo, individual e coletiva, múltipla e desacelerada. A memória, ao se enraizar no concreto, na imagem, no gesto e no objeto, busca lugares em que possa se alimentar de lembranças e de esquecimentos (Nora, 1993, p. 9). Esses lugares, que compreendem aspectos do tipo funcional, material e simbólico não se excluem e coexistem no tempo, têm como função relembrar o passado continuamente em uma tentativa de manter ativos laços de pertença e vínculos de identidades. $\mathrm{O}$ esfacelamento desses vínculos e a crise, daí decorrente, seriam, de acordo com Nora, traços da contemporaneidade, quando lembranças sáo transformadas em estoque material na tentativa de fixar um determinado estado de coisas (Nora 1993, p. 21-28).

Perceber o corpo como construtor de memória, como um lugar no qual nascem e se ancoram gestos e movimentos, é entendê-lo como absoluto e relativo, em que a materialidade da carne se une à particularidade simbólica dos sentidos e imagens por e nele criado. Náo cabe tratar a memória de uma perspectiva cronológica linear sem qualquer preocupação historiográfica, mas em suas descontinuidades temporais criadas a partir do próprio ato de lembrar/esquecer, processos que reelaboram significados e sentidos. Maurice Halbwachs (2006) apontou como a memória individual, desde as lembranças mais particulares, está inserida no meio social, estruturando-se e sofrendo influências desse. Ao conceituar os quadros sociais da memória, Halbwachs aponta para essa qualidade de saber, já que esses são os instrumentos que a memória coletiva utiliza para recompor o passado, e assim elaborar sua história. Por não ser fixa e invariável, a memória, como construção humana, passa por transformaçóes, que se alteram de acordo com o sistema de valores vigente. A leitura de um livro, a apreciaçáo de uma obra de arte, ou de uma coreografia, por exemplo, ganham significaçóes distintas ao longo do tempo, já que o ponto de vista social daqueles que usufruem dessas obras, organizado a partir das relaçóes socioculturais, é cambiante, em que negociaçóes, disputas e conflitos estão presentes (Cerbino, 2009). 
As relaçóes entre memória e identidade tratadas pelo antropólogo Joël Candau (2011) são de especial interesse por sua contribuição no entendimento da memória não como algo uno, mas pleno de sutilezas e diferenciaçôes, ao decompô-la em três níveis: protomemória, memória de evocação e metamemória. Ao expor sobre a protomemória, Candau aponta que esta é a própria memória social incorporada, presente nos gestos, nas práticas e nas linguagens, mas realizada de maneira quase automática, agindo diretamente no corpo (Candau, 2011, p. 22-23). A memória propriamente dita é o segundo tipo por ele apresentado, em que a recordação voluntária se estende aos saberes, às crenças, aos sentimentos e às sensaçóes. $\mathrm{O}$ terceiro tipo, a metamemória, diz respeito à construção identitária em si, à representação que fazemos de nossas lembranças, como lidamos com elas e dos usos que fazemos delas. Nesse sentido, essa última formulação aproxima-se do conceito de memória coletiva de Halbwachs, pois de acordo com Candau, apenas a metamemória pode ser partilhada, já que se trata de um conjunto de representaçóes da memória (Candau, 2011, p. 133).

\section{O Original Ballet Russe na cidade do Rio de Janeiro}

A cidade do Rio de Janeiro, como centro político e cultural, tornouse, a partir da década de 1940, mais cosmopolita, firmando-se na vida econômica e social brasileira, em um lento e complexo processo de reorganização territorial e espacial do país ${ }^{9}$. Espalhados pela cidade, encontravam-se cinemas, teatros e cassinos, com vários espetáculos em cartaz, proporcionando mais trabalho para os profissionais da dança. A criação das companhias cinematográficas Atlândida, em 1941, no Rio de Janeiro, e Vera Cruz, em 1949, em São Paulo, ampliaram ainda mais as oportunidades para bailarinas e bailarinos, já que era significativa a presença de números musicais e dança nos filmes produzidos.

Perceber essas mudanças é também entender que após a Segunda Guerra Mundial deu-se a emergência não só de um outro padrão monetário, o dólar, como também de um novo modelo cultural, o norte-americano. A publicidade, os livros e, principalmente, o cinema, podem ser apontados como os veículos responsáveis por essa disseminação. A afirmação do star system 
hollywoodiano e o culto aos seus artistas foram algumas das características desse padrão, e a dança produzida no contexto desse projeto estético-cultural não ficou à margem desse processo. $\mathrm{Na}$ verdade, a estrutura de uma companhia de balé há muito já tratava seus primeiros-bailarinos como estrelas, o que já existia desde o período romântico no século XIX, como, por exemplo, com a bailarina ítalo-sueca Marie Taglioni (1804 - 1884), na Ópera de Paris. Mas a principal modificação ocorrida, na década de 1940, foi o fato desses profissionais buscarem o status de grandes estrelas internacionais do cinema, ao utilizar a mídia náo apenas para vender os espetáculos dos quais participavam, como também para se autopromoverem. Como a bailarina Tamara Toumanova (1919 - 1996), que fez sua estreia no cinema, em 1944, ao protagonizar Days of glory $^{10}$, ao lado do ator norte-americano Gregory Peck (1916-2003).

Ao mesmo tempo, a dança buscava formas de apresentaçáo cênica, tanto em seus aspectos técnicos quanto estéticos, que levassem em conta as transformaçóes em curso $^{11}$. Uma dessas possibilidades foi o diálogo entre o balé e a dança moderna, que, na década de 1930, já havia alcançado a cena internacional, chegando aos palcos cariocas com as turnês do Original Ballet Russe, quando os três primeiros balés sinfônicos ${ }^{12}$ criados pelo bailarino e coreógrafo russo Léonid Massine (1896 - 1979) foram mostrados.

O Original Ballet Russe realizou três grandes temporadas na cidade do Rio de Janeiro ${ }^{13}$, todas na década de 1940, sempre no Theatro Municipal. A primeira ocorreu de 20 de abril a 10 de maio de 1942; a segunda iniciou-se em 5 de maio e foi até 1 de junho de 1944; e a terceira dividiu-se em duas etapas: de 3 a 14 de junho e de 10 a 23 de agosto de 1946 . Fizeram parte do elenco, nessas três ocasióes, importantes nomes da dança internacional como Andre Eglevsky (1917 - 1977), Alexandra Danilova (1903 - 1997), Alicia Markova (1910 - 2004), David Lichine (1910 - 1972), Geneviève Moulin, George Zoritch (1910-1983), Igor Youskevitch (1913 - 1997), Irina Baronova (1919 - 2008), Lubov Tchernicheva (1890 - 1976), Nana Gollner (1919 - 1980), Nina Verchinina (1910 - 1995), Tamara Grigorieva (1918 - 2010), Tamara Toumanova (1919 - 1996), Tatiana Leskova (1922), Tatiana Riabouchinska (1917 - 2000), Tatiana Stepanova (1924 - 2009), Yurek 
Shabelewski (1910 - 1983), entre outros profissionais (Chaves, 1971, p. 284, 286, 287-288).

Em sua estreia no Rio de Janeiro, o Original Ballet Russe foi apresentado por Jaques Corseuil, na revista Ilustração Brasileira, de maio de 1942, como a "[...] companhia que mantinha a tradiçấo" do que chamava balés russos $(1942$, p. 28). Denominação que se referia, de modo geral, às companhias russas, reconhecidas pelo apuro técnico de seus bailarinos, como também pelo repertório que apresentavam. Cabe salientar como o termo russo é utilizado por Corseuil para adjetivar a própria ideia de balé, como uma qualidade a ser alcançada, parâmetro que deveria balizar açôes e projetos relativos ao balé que aqui se fazia (Cerbino; Cerbino, 2010).

Para além de apontar e reafirmar a qualidade da companhia, havia a clara preocupação do crítico em mostrar como o balé, especificamente o russo, tinha potência para atuar no desenvolvimento da cultura local, operando como vetor para a constituição do bailado nacional e na formaçáo de profissionais da dança. Discurso que repetiria em seus textos, durante as passagens da companhia pela cidade, em especial nas duas primeiras, inseridas no contexto estadonovista de Vargas. Um pensamento corroborado pelo próprio Coronel de Basil, para ele, o Original Ballet Russe deveria ser percebido como "[...] uma escola de técnica pura e um exemplo de desenvolvimento da arte mais completa", que tinha como missáo manter a tradição do passado e realizar um "[...] trabalho constante no presente para preservar o futuro" (Corseuil, 1942, p. 28).

Em sua primeira passagem pelo Theatro Municipal do Rio de Janeiro, a companhia apresentou dezenove coreografias, divididas entre cinco récitas de assinatura, seis vesperais e oito espetáculos extras, perfazendo um total de cinquenta performances. As que mais se repetiram foram Les sylphides ${ }^{14}, O$ lago dos cisnes, em versão de dois atos, Baile dos graduados ${ }^{15}$, Bodas de Aurora, versão de um ato para $A$ bela adormecida ${ }^{16}$, Paganini ${ }^{17}$, Os presságios ${ }^{18}$, Choreartium $^{19}$ e $O$ espectro da rosa ${ }^{20}$ (Chaves Jr, 1971, p. 284).

Na temporada seguinte, em 1944, no primeiro texto que escreveu sobre o retorno da companhia à cidade, além de ressaltar a importância dessa presença para movimentar a cena cultural carioca, Jaques Corseuil chamou 
atenção para a renovação do elenco. Após dois anos em excursão pela América Latina, alguns bailarinos tinham optado por permanecer nas cidades em que se apresentavam, como Dimitri Rostoff, que decidiu ficar em Lima, no Peru, e lá abrir uma escola de balé, ou então regressar ao seu país de origem, caso de H. Algenaroff (1903 - 1967), que voltou para a Inglaterra, e Nana Gollner (1920 - 1980), para os Estados Unidos. Ressaltava, porém, que esse processo era comum nas grandes companhias e "[...] fundamental para que novos talentos pudessem surgir e assim ganhar experiência de palco" (Corseuil, A cena muda, 1944b, p. 8-9).

O grupo retornou basicamente com o mesmo repertório, ao qual acrescentaram-se Icaro ${ }^{21}$, Ilha dos ceibos, L'apré-midi d'un faune, Luta eterna, Mulheres de bom humor $^{22}$ e Sinfonia fantástica ${ }^{23}$. Foram realizadas oito récitas de assinaturas, sete vesperais, duas extras e uma participação no $165^{\circ}$ Sarau da Cultura Artística, em um total de cinquenta e quatro performances (Chaves Jr, 1971, p. 286). A grande diferença em relação à temporada anterior foi ter sido possível assistir aos três balés sinfônicos de Léonid Massine - Os presságios, Choreartium e Sinfonia fantástica ${ }^{24}$ - que ao lado de Baile dos graduados, Danúbio azul ${ }^{5}$, O lago dos cisnes, Les sylphides, Paganini e Schéhérazade foram os mais apresentados.

Na segunda passagem do Original Ballet Russe, em 1944, Corseuil insistiu na necessidade de uma política de apoio ao balé nacional e de se investir na formação dos bailarinos brasileiros. Em seu texto $A$ volta do ballet russo, publicado na edição de abril de $A$ cena muda (1944a, p. 8-9), ressaltou como a manutenção de um bom repertório e das oportunidades que novos bailarinos e coreógrafos tinham com De Basil eram fundamentais para o êxito do grupo, o que também deveria acontecer com o Corpo de Baile do Theatro Municipal. Na revista Vida de maio, voltou ao tema ao destacar ser esse o tipo de orientação que a companhia oficial da cidade, que não realizou temporada oficial naquele ano, mais precisava. Corseuil (1944c, p. 48-49) foi enfático ao afirmar que "[...] quanto mais se reconhece o que há de bom num Ballet estrangeiro, mais vontade se tem de possuir um Ballet nacional segundo esse alto padrão" (Cerbino; Cerbino, 2010). E o modelo a ser seguido, naquele momento, segundo Corseuil, era o Original Ballet Russe, por meio do 
qual se poderia ter contato com o que havia de melhor, tanto em termos coreográficos quanto em técnica de dança.

No balanço geral que fez da temporada de 1944, Jaques Corseuil (Ilustração Brasileira, 1944d, p. 40) ressaltou o perfil conservador do repertório, considerando a temporada "[...] útil, não só pela educaçáo do gosto para o bailado clássico, (...) mas pela valorização da dança”. Ao apresentar um conjunto de coreografias que englobava os balés tradicionais de Marius Petipa ${ }^{26}$ (1818 - 1910), as inovaçóes de Léonid Massine, e a releitura dos clássicos por Michel Fokine, apontou que o carioca teve chance de assistir ao vivo a um verdadeiro "[...] documentário sobre as origens do balé". Respondia assim as críticas feitas à companhia, que havia sido comparada a um museu, o que em sua opiniáo deveria ser entendido como um elogio, já que se tratava de um "[...] museu vivo, do gesto, do movimento" (Corseuil, 1944d, p.40), e fundamental para a continuidade do balé. Corseuil lamentou ainda a curta duraçáo da temporada e o número reduzido de espetáculos populares (1944d, p.40). Cabe perceber como, em seus textos, Corseuil faz questáo de defender o balé, especialmente o que chamava de tradição russa do balé, como modelo para a estruturação de uma companhia, fosse em termos de encenação, fosse como técnica a ser seguida.

Foi nesse ano que alguns bailarinos do grupo do Coronel de Basil decidiram permanecer no Rio de Janeiro, como Anna Volkova (1917 - 2013), James Upshaw (1921 - ?), Lydia Kuprina e Tatiana Leskova (1922). Volkova, Upsahw e Kuprina, após um período, retornaram às viagens, Leskova aqui ficou e tornou-se uma das grandes referencias do balé no Brasil, estabelecendo-se no Rio de Janeiro, onde formou geraçóes de bailarinas e bailarinos e dirigiu o Ballet do Theatro Municipal em várias ocasióes, entre 1950 e 1990 (Pereira, 2001). Outro importante nome para o balé nacional foi Yurek Shabelewski ${ }^{27}$ que, entre idas e vindas, fixou-se definitivamente, a partir de 1971, em Curitiba, onde esteve à frente por cinco anos do Corpo de Baile do Teatro Guaíra, com as funçôes de maître de ballet e coreógrafo.

Ao retornar em 1946, o Original Ballet Russe realizou a temporada oficial de bailados do Theatro Municipal, o que já havia ocorrido em 1944. Apresentada em duas partes, a primeira no início de julho e a segunda em 
final de agosto, o grupo voltou a mostrar coreografias que o consagraram anteriormente, em um total de quarenta e seis performances, com oito récitas de assinatura, quatro vesperais e quatro extras (Chaves Jr., 1971, p. 288).

A novidade ficou por conta da inclusão de quatro obras ainda desconhecidas pelo público carioca: Cain e Abel ${ }^{28}$, Pássaro de fogo ${ }^{29}$, Valse triste ${ }^{30}$ e Yara. Essa última, tendo como tema a seca no Nordeste, estreou, em julho, em São Paulo, para depois ser mostrada no Rio de Janeiro. Chegou-se a considerar o assunto escolhido, a vida dos retirantes, "uma ousadia bem grande" para o primeiro balé brasileiro a fazer parte do repertório de uma grande companhia internacional (Bento, 1946, seção 2, p. 1). O balé constou do programa carioca três vezes, e fez parte do repertório que a companhia apresentou em sua temporada novaiorquina, no Metropolitan Opera House, e na excursão costa a costa, nos Estados Unidos, de 1946/1947 (Original Ballet Russe, 1946).

Foi também nesse ano que, junto com a companhia e como uma de suas artistas hóspedes, ao lado de Irina Baronova e Lubov Tchernicheva, veio, pela primeira vez ao Rio de Janeiro, a bailarina russa, depois naturalizada brasileira, Nina Verchinina $(1910$ - 1995). Ocasião em que foi convidada por Antonio Vieira de Melo, diretor do departamento de Difusão Cultural da Prefeitura, a permanecer na cidade para assumir como diretora, maître de ballet e coreógrafa do então Corpo de Baile do Theatro Municipal, que na época passava por um momento delicado, com poucos ensaios e ainda, em meados de 1946, sem récitas programadas. O fato do Original Ballet Russe realizar a temporada oficial de balé do Theatro Municipal, o que já havia ocorrido em 1944, era um significativo indício das dificuldades que o Corpo de Baile atravessava, lutando para se manter como uma companhia de balé profissional, com bailarinos e bailarinas de bom nível técnico e um repertório que incluísse tanto obras novas, como Maracatu do Chico Rei ${ }^{31}$, quanto coreografias já reconhecidas, como O Espectro da Rosa, Petruchka ${ }^{32}$ e Les Sylphides ${ }^{33}$, entre outras.

Em uma matéria para $O$ Globo, na qual apresentava Nina Verchinina como um dos principais nomes na formação do moderno Ballet Russo, Corseuil afirmava a importância da presença da artista no Brasil e assim, “[...] 
finalmente, se investir na preparação de bailarinos brasileiros" (Corseuil, 1946, p. 5).

Com contrato assinado para duas temporadas, 1947 e 1948, Verchinina, no entanto, encontrou grande resistência para implementar suas ideias e levar adiante seu trabalho, como as novas propostas de preparação corporal, em especial o aquecimento no chão para as aulas de dança moderna (Cerbino, 2001, p. 32). Além disso, questôes financeiras e administrativas do próprio Theatro Municipal, como atrasos no pagamento de seu salário e dificuldades em montar uma temporada, tornaram sua permanência inviável. Em março de 1948, retornou à Europa, onde reencontrou a companhia do Cel. W. De Basil.

\section{Para Concluir}

O Original Ballet Russe permaneceu em excursão pelas Américas durante os anos da Segunda Guerra Mundial, de 1942 a 1946, quando realizou temporadas em vários países: Argentina, Brasil, Chile, Colômbia, Costa Rica, Cuba, El Salvador, Estados Unidos, Equador, Guatemala, Honduras, México, Peru e Uruguai. Pode-se dizer que, em muitas das cidades em que se apresentou, deixou importantes referencias para a produção local de balé, tanto por meio de suas performances, quanto pelas aulas que muitos de seus bailarinos e bailarinos ministraram nessas localidades (García-Márquez, 1990, p. 316).

Quando a companhia fez sua estreia no Rio de Janeiro, em 1942, os espetáculos de dança sucediam-se com certa frequência no Theatro Municipal. Entre os grupos que estiveram na cidade antes dessa data, dois se destacam: em 1940, o Ballet Russe de Monte Carlo, com direçáo artística de Leonid Massine, e, no ano seguinte, o American Ballet, dirigido por George Balanchine (1904-1983). Contudo, foi apenas a partir de 1942, com o Original Ballet Russe, que o ideal diaghleviano de balé pode ser conferido mais de perto pelos profissionais que atuavam na cidade.

O grupo do Coronel de Basil se apresentou aqui três vezes, ao longo de quatro anos, passando temporadas de cerca de dois meses na cidade, quando convivia com bailarinos locais, críticos e empresários da área. Como era 
prática, profissionais de cada localidade eram contratados para compor as fileiras da companhia: Leda Iuqui (1922 - 2012) dançou nas duas primeiras temporadas, 1942 e 1944; Lorna Kay participou da segunda, seguindo, depois, viagem com o grupo, retornando ao Brasil em 1944; Marília Franco (1920 - 2006), bailarina paulista que, ao se casar com Vaslav Veltchek ${ }^{34}$ (1896 - 1967), transferiu-se para o Theatro Municipal do Rio de Janeiro, também foi contratada em 1944, e continuou na companhia até meados de 1945. Na terceira passagem do Original Ballet Russe, em 1946, participou como solista (Cerbino; Cerbino, 2010).

Para além da simples apresentaçóes de espetáculos, essas turnês representaram a oportunidade que os profissionais da dança, aqui em atividade, tiveram para ampliar seus conhecimentos da técnica de balé, assim como entrar em contato com um amplo repertório. Afinal, não fazia muito tempo que o então Corpo de Baile do Theatro Municipal do Rio de Janeiro havia realizado sua primeira temporada oficial.

Outro importante aspecto das temporadas Original Ballet Russe na cidade do Rio de janeiro foi a participação de seus bailarinos nos espetáculos de dança da cidade. Embora de modo tímido no início, essa inserção se acentuou nas temporadas seguintes. De um modo geral, esses profissionais eram solistas ou do corpo de baile, e não os primeiros-bailarinos. Lidia Kuprina, James Upshaw e Yurek Shabelewski, bailarinos da companhia em 1942, permaneceram no Rio e participaram, no ano seguinte, do show Em busca da beleza, em outubro, no Cassino Copacabana, que teve coreografia do tcheco Vaslav Veltchek e arranjos do compositor, pianista e maestro brasileiro Radamés Gnatalli $(1906-1988)^{35}$.

Em 1944, Anna Volkova, Tamara Grigorieva e Tatiana Leskova dançaram em shows do Copacabana, como Ciclo eterno, no mês de agosto, Flagrantes da vida, em outubro, e Meia-noite na meia-noite, em dezembro ${ }^{36}$, e no espetáculo de fim de ano, promovido pela Federação Atlética dos Estudantes. Kuprina e Upshaw também atuaram nesse espetáculo, e, em 1946, como artistas convidados do Ballet da Juventude, que entáo fazia suas primeiras apresentaçóes. Nesse mesmo ano, Upshaw participou como bailarino do filme Caídos do céu, comédia musical produzida pela Cinédia e dirigida por Luiz 
de Barros. Quatro anos depois, em 1950, Kuprina e Upshaw tomaram parte de outra comédia musical, Um beijo roubado, também conhecido como Noites em Copacabana, produção da Cinédia e direção de Leo Marten ${ }^{37}$.

Ao longo de 1945, esses bailarinos igualmente marcaram uma forte presença em diferentes shows do Cassino Copacabana, como em Máscaras, que estreou em janeiro, Variety, em maio, e Olimpiada, em outubro, esses dois últimos com coreografia Vaslav Veltchek. Todos esses espetáculos - é importante lembrar - contaram com a participação da primeira-bailarina Leda Iuqui, assim como o Cassino da Urca também tinha uma primeira-bailarina, Madeleine Rosay, como sua principal estrela, ambas do Corpo de Baile do Theatro Municipal.

Nos trechos de algumas das matérias assinadas por Jaques Corseuil, aqui apresentadas, percebe-se como o crítico fez questáo de ressaltar, de acordo com sua perspectiva, o caráter formador e informativo que as temporadas tiveram, ao atuar na "[...] educação do gosto para o bailado" dos espectadores, ensinando-os sobre a história da dança (Ilustração Brasileira, 1946, p. 25).

É possível observar como a produçáo crítica de Corseuil operava em duas frentes: no campo da estética, ao apontar as referencias técnicas que deveriam ser adotadas pelo balé nacional, e na formação de um ambiente favorávelà dança, ao indicar que as temporadas do Original Ballet Russe deveriam fazer parte de um programa de educaçáo via a dança. Trata-se de perceber as motivaçóes artísticas e políticas inseridas em sua escrita, e que faziam parte do ideal nacionalista instaurado pelo Estado Novo. As escolhas que ele fez para os temas de suas matérias, assim como as convençóes de época que seguiu e afirmou, são importantes informações, a partir do olhar crítico atual, sobre as mudanças de perspectiva que ocorreram em relação ao balé. 


\section{Revista

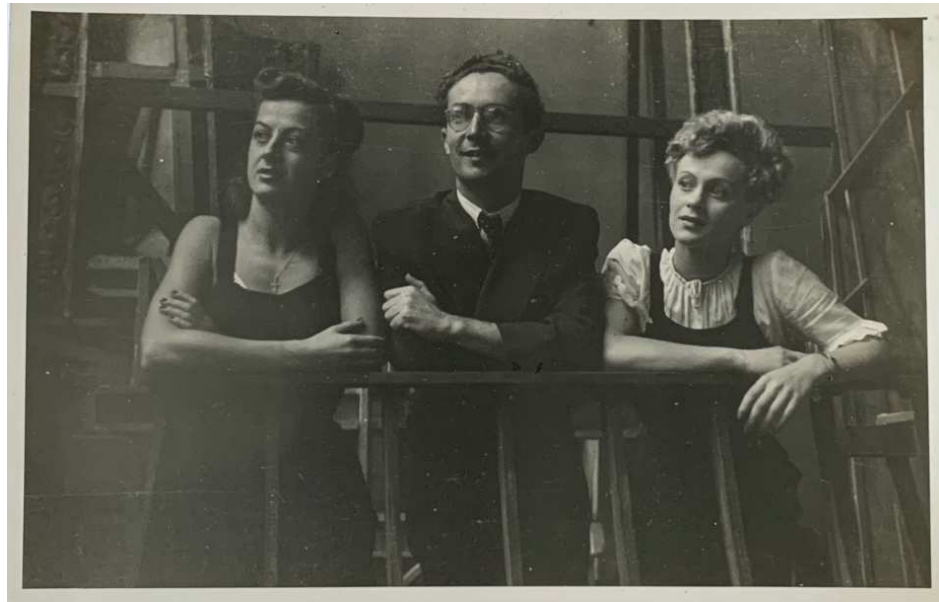

Figura 1 - Anna Volkova, Jaques Corseuil e Tatiana Leskova, no Theatro Municipal do Rio de Janeiro, na primeira temporada do Original Ballet Russo na cidade, em 1942. Foto: Kurt Paul Klagsbrunn

Fonte: Acervo Jaques Corseuil.

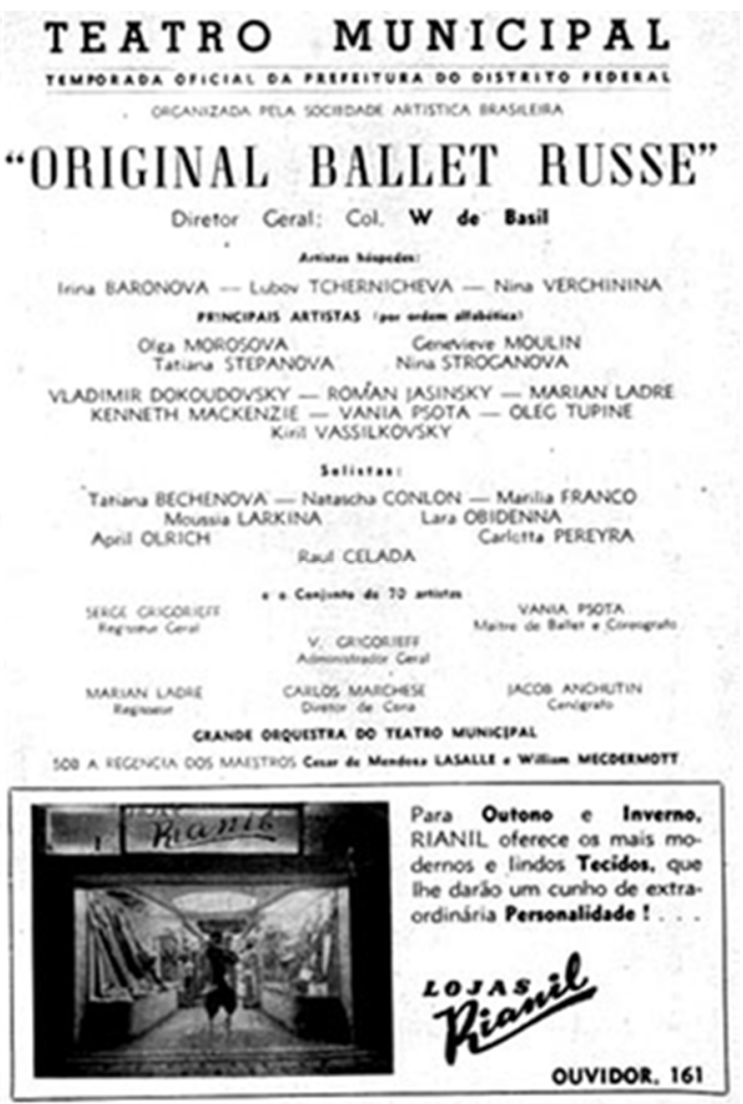

Figura 2 - Programa do Original Ballet Russe no Rio de Janeiro, em 1946, quando a companhia realizou a temporada oficial de balé do Theatro Municipal.

Fonte: Acervo Jaques Corseuil. 


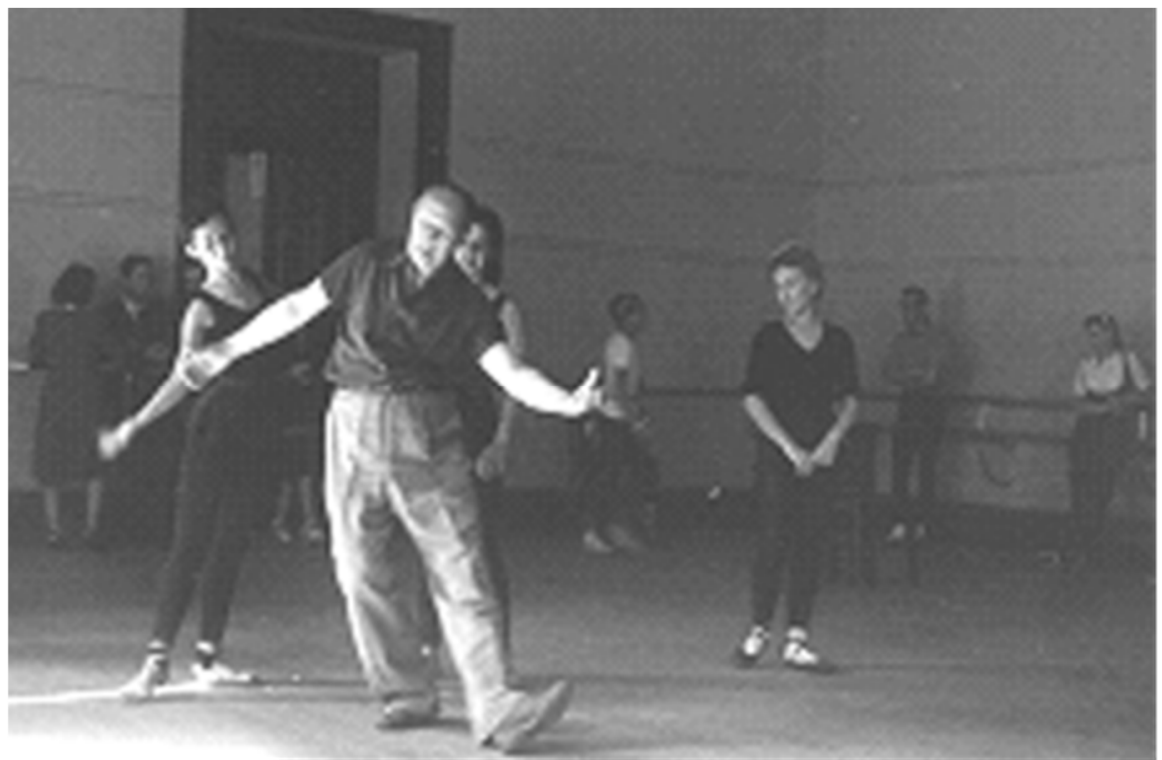

Figura 3 - Ensaiador Sergei Grigoriev (1883 - 1968) preparando a companhia Original Ballet Russe no Theatro Municipal, em 1946. Grioriev exerceu essa função com o OBR de 1932 a 1952. Foi também ensaiador geral dos Ballet Russes de Diaghilev, de 1909 a 1929. Foto: Kurt Paul Klagsbrunn.

Fonte: Acervo Jaques Corseuil.

\section{Notas}

1 Ao longo dos vinte anos em que esteve em atividade, o Ballets Russes de Diaghilev teve, como colaboradores em suas produçóes, os músicos Claude Debussy, Darius Milhaud, Erik Satie, Igor Stravinsky, Maurice Ravel, Serge Prokofiev, entre outros; e os artistas visuais Alexandre Benois, Andre Derain, Giacomo Balla, Henri Matisse, Juan Gris, Léon Baskt, Michel Larionov, Natalia Gontcharova, Nicholas Roerich, Pablo Picasso etc. Como coreógrafos residentes, a companhia contou, em diferentes períodos, com Michel Fokine (1880 1942), Vaslav Nijinsky (1889 - 1950), Léonid Massine (1896 - 1979), Bronislava Nijinska (1891 - 1972) e George Balanchine (1904 - 1983) (Garafola 1998, p. 399-415).

2 O grupo de Diaghilev apresentou os primeiros espetáculos de balé no Theatro Municipal do Rio de janeiro, quando realizou, em 1913, sua primeira temporada carioca, perfazendo doze récitas, de 17 de outubro a 1 de novembro. Retornou quatro anos depois, em 1917, de 14 a 26 de agosto, ocasião em que deu onze espetáculos (Chaves Jr., 1971, p. 270, 271). 
3 Para um aprofundamento das inovaçóes cênicas propostas pelo grupo de Diaghilev, ver GARAFOLA, Lynn. Diaghilev's Ballets Russes. New York: Da Capo Press, 1998.

4 Para um aprofundamento sobre a política cultural do Estado Novo, ver SCHWARTZMAN, Simon; BOMENY, Helena, M. B.; COSTA, Vanda M. R (orgs.). Tempos de Capanema. São Paulo: Paz e Terra: FGV, 2000.

5 O comum nesse período era que críticos de artes visuais, música e teatro também produzissem textos sobre dança, como: Antonio Bento (1902 - 1988), do Diário Carioca; Mário Nunes (1886 - 1968), do Jornal do Brasil; JIC, como assinava João Itiberê da Cunha (1870 - 1953), e Eurico Nogueira França (1913 - 1992), do Correio da Manhá; Mário Domingues, do Correio da Noite, D’Or, pseudônimo de Ondina Ribeiro Dantas, do Diario de Noticias; Grock, da revista O Cruzeiro, e Ruben Navarra (1917 - 1955), do jornal A Manhã (Cerbino, 2011, p. 4).

6 Para um aprofundamento sobre o tema, ver PEREIRA, Roberto. A formaçáo do balé brasileiro. Rio de Janeiro: Editora FGV, 2003.

7 Para uma discussáo aprofundada dos processos constituintes do Ballet da Juventude, ver CERBINO, Beatriz. Cenários cariocas: o Ballet da Juventude entre a tradição e o moderno. Niterói. Tese (Doutorado em História) - Universidade Federal Fluminense, Niterói, 2007.

8 No Brasil, cabe destacar a pesquisa desenvolvida por Holly Cavrel, em seu livro Dando corpo à história (2015), e as publicaçóes de Cássia Navas, em especial Dança, História, Ensino e Pesquisa / Danse, Histoire, Formation, Recherche (2017), organizado em conjunto com Isabelle Launay e Henrique Rochelle obras que abordam, de maneira consistente, as questóes do corpo que dança.

9 Para um aprofundamento sobre o tema, ver SANTOS, Milton. A urbanizaçáo brasileira. 5a edição. São Paulo: Edusp, 2005.

10 Filme estadunidense de 1944, do gênero drama de guerra, dirigido por Jacques Tourneur e estrelado por Tamara Toumanova, Gregory Peck, Alan Reed e Maria Palmer. 
11 Para uma discussão sobre esse tema, ver GARAFOLA, Lynn. Legacies of twentieth century dance. Middletown: Wesleyan University Press, 2005.

12 Os três primeiros balés sinfônicos, dos dez criados por Massine, assim chamados por utilizarem sinfonias como trilha sonora, foram: Les Présages (1933), com a Sinfonia no. 5, de Pyotr Tchaikovsky; Choreartium (1933), com a Sinfonia no. 4, de Johannes Brahms; e Sinfonia fantástica (1936), com a Sinfonia fantástica, de Hector Berlioz (Craine; Mackrel 2000, p. 319).

13 Como era de praxe, após os espetáculos no Rio, a companhia também se apresentava na cidade de São Paulo, no Teatro Municipal, temporadas que não serão tratadas neste texto.

14 Balé em um ato, músicas de Frédéric Chopin, cenário e figurinos de Alexandre Benois. Estreou em 2 de junho de 1909, no Teatro Chatelet, em Paris (Craine; Mackrell, 2000, p. 459-460).

15 Balé em um ato, coreografia de David Lichine, música de J. Strauss, arranjos de A. Dorati, cenários e figurinos de A. Benois. Estreou no Teatro Real de Sidnei, em 28 de fevereiro de 1940 (Craine; Mackrell, 2000, p. 211).

16 Balé em três atos, música de Piotr Tchaikovsky, libreto de Marius Petipa e Ivan Vsevolozhsky, figurinos de Vsevolozhsky, cenários de Ivan Andreyev, Mikahil Bocharov, Konstantin Ivanov, Heinrich Levgot e Matvei Shishkov, estreou no Teatro Maryinsky, em 16 de janeiro de 1890 (Craine; Mackrell, 2000, p. 437).

17 Balé em um ato, coreografia de Michel Fokine, música de Rachmaninov, libreto de Rachmaninov e Fokine, cenários e figurinos de Soudekine, estreou no Convent Garden, em Londres, em 30 de junho de 1939 (Craine; Mackrell, 2000, p. 357).

18 Balé em quatro movimentos, com a Quinta Sinfonia de P. Tchahikovsky, coreografia de Léonid Massine, cenário e figurinos de André Masson, libreto de Léonid Massine. Estreou no Teatro de Monte Carlo, em Monte Carlo, em 13 de abril de 1933 (Craine; Mackrell, 2000, p. 378).

19 Balé em quatro movimentos, com a Quarta Sinfonia de J. Brahms, coreografia de Léonid Massine, cenário e figurinos de Constantine Terechkovich e Eugène 
Lourié. Estreou no Teatro Alhambra, em Londres, em 24 de outubro de 1933. (Craine; Mackrell, 2000, p. 104)

20 Balé em um ato, coreografia de Michel Fokine (1880 - 1942), libreto de J. L. Vaudoyer, música de Carl Maria von Weber, cenário e figurinos de Léon Bakst (1866 - 1924). Estreou em 19 de abril de 1911, no Teatro de Monte Carlo, em Monte Carlo (Craine; Mackrell, 2000, p. 446).

21 Balé em um ato, coreografia de Serge Lifar, música de Lifar com instrumentação de G. Szyfer, cenário e ficurinos de P. Larthes, estreou na Ópera de Paris, em 9 de julho de 1935 (Craine; Mackrell, 2000, p. 244).

22 Balé em um ato, coreografia e libreto de Léonid Massine, música de Domenico Scalartti, com arranjos de Vincenzo Tommasini, cenário e figurinos de Léon Bakst, estreou no Teatro Costanzi, em Roma, em 12 de abril de 1917 (Craine; Mackrell, p. 208).

23 Balé em um ato e cinco cenas música de Hector Berlioz, cenários e figurinos de Christian Bérard, estreou no Convent Garden, em Londres, em 24 de julho de 1936 (Craine; Mackrell, 2000, p. 461).

24 Balé em um ato, coreografia de Léonid Massine, música de Berlioz, cenários e figurinos de Bérard. Estreou no Covent Garden, em Londres, em 24 de julho de 1936 (Craine; Makrel, 2000, p. 461).

25 Coreografia de Serge Lifar, música de J. Strauss, arranjos de Eugene Fuerst, cenários e figurinos de Conte Etienne de Beaumont, estreou em Sidnei, em 9 de fevereiro de 1940. Foi, na verdade, uma polêmica remontagem de Le beau Danube, de Léonid Massine, feita a revelia do autor por Lifar que rearrumou as cenas e deu um novo nome à coreografia (Craine; Mackrell, 2000, p. 56).

26 Apontado como o mais importante coreógrafo da história do balé clássico, o francês, depois naturalizado russo, Petipa migrou para São Petersburgo em 1847, onde permaneceu por sessenta e três anos, passando de bailarino a maître de ballet, onde criou e revisou cerca de cinquenta coreografias para os teatros Imperiais em São Petersburgo e Moscou. Entre suas obras pode-se citar: Don Quixote (1869), La Bayadére (1877), A bela adormecida (1890), O lago dos cisnes (1895) e Raymonda (1898) (Craine; Mackrel, 2000, p. 368-369). 
27 O documentário Shabelewski, curta-metragem de 17 minutos sobre a vida do bailarino, foi produzido e dirigido por Nivaldo Lopes, em 2005.

28 Balé em um ato, coreografia e libreto de David Lichine, música de Richard Wagner, arranjos de William McDermott, cenário e figurinos de Miguel Pietro. Estrou no Palácio das Belas Artes, na Cidade do México, em 8 de março de 1946 (Walker, 1983, p. 258-259).

29 Balé em um ato, coreografia de Michel Fokine, música de Igor Stravinsky, cenário e figurinos de Alexander Golovin e Leon Bakst. Estreou na Ópera de Paris, em 25 de junho de 1910 (Craine; Mackrell, 2000, p. 183).

30 Balé em um ato, coreografia de Nina Verchinina, música de Jean Sibelius, cenário e figurinos de Jan Zach (Walker, 1983, p. 278-279).

31 Balé em um ato, coreografia de Maria Olenewa, música de Francisco Mignone, cenário e figurinos de Santa Rosa. Estreou em 08 de julho de 1939, no Theatro Municipal do Rio de Janeiro (Pereira, 2003, p. 134, 139).

32 Balé em um ato, coreografia de Michel Fokine, libreto de Alexandre Benois (1870 - 1960) e Igor Stravinsky (1882 - 1971), música de Stravinsky, cenário e figurinos de Alexander Benois. Estreou em 13 de junho de 1911, no Teatro Chatelet, em Paris (Craine; Mackrell, 2000, p. 371).

33 Balé em um ato, coreografia de Michel Fokine, música de Chopin. A primeira versão estreou em 23 de fevereiro de 1907, no Teatro Maryinsky, com o nome de Chopiniana. No ano seguinte, em 21 de março, uma segunda versão foi apresentada, também no Teatro Maryinsky. A terceira versão, já renomeada como Les sylphides, estreou em 2 de junho de 1909, no Teatro Chatelet, em Paris (Craine; Mackrell, 2000, p. 459).

34 Vaslav Veltchek chegou ao Rio de Janeiro em 1939, a convite do Prefeito Henrique Dodsworth, para ajudar a organizar, em conjunto com Maria Olenewa, a temporada no Theatro Municipal. Com a eclosão da II Guerra Mundial permaneceu no Brasil até 1953, tendo participação fundamental no desenvolvimento do balé do Rio de Janeiro e de São Paulo. A partir de 1953, atuou como coreógrafo convidado no Uruguai, Venezuela e Espanha, fixando-se, definitivamente, no Brasil, de 1965 até o ano de seu falecimento (Faro, 1988, p. 29-33). 
35 Jornal O Globo, 24 de setembro de 1942; jornal Correio da noite, 1 de outubro de 1943; Revista A cena muda, 27 de março de 1945.

36 Jornal Correio da noite, 16 de outubro e 16 de dezembro de 1944.

37 Disponível em <www.us.imdb.com/title/tt0180589/>. Acesso em 08 de março de 2021.

\section{Referências}

ADSHEAD-LANSDALE, Janet; LAYSON, June (orgs.). Dance history: an introduction. Nova York: Routledge, 1995.

BENTO, Antonio. "O bailado Iára”. Diário Carioca, Rio de Janeiro, seção 2, p. 1, 18 de agosto de 1946 .

BLOCH, Marc. Apologia da história ou o ofício do historiador. Rio de Janeiro: Zahar, 2001.

BURKE, Peter. O que é história cultural? Rio de Janeiro: Jorge Zahar Ed., 2005.

CANDAU, Joël. Memória e identidade. São Paulo: Contexto, 2011.

CAVREL, Holly Elizabeth. Dando corpo à história. Curitiba: Ed. Prismas, 2015.

CERBINO, Beatriz. "Jaques Corseuil e a crítica de dança no Brasil". O Percevejo online, periódico do PPGAC/UniRio, V. 3, n. 1, 2011.

CERBINO, Beatriz; CERBINO, Ana Luiza. O Original Ballet Russe no Rio de Janeiro: memórias em movimento. X Encontro Nacional de História Oral - Testemunhos: História e política. UFPE. Recife, 26 a 30 de abril de 2010.

CERBINO, Beatriz. "Dança e memória: usos que o presente faz do passado". In: BOGÉA, Inês (org.). Primeira estaçáo: ensaios sobre a São Paulo Companhia de Dança. $1^{a}$. Edição. São Paulo: Imprensa Oficial do Estado de São Paulo, v. 1, p. 33-47, 2009.

CERBINO, Beatriz. Cenários cariocas: o Ballet da Juventude entre a tradição e o moderno. Niterói. Tese (Doutorado em História) - Universidade Federal Fluminense, Niterói, 2007. 
CERBINO, Beatriz. Nina Verchinina: um pensamento em movimento. Série Memória 8. Rio de Janeiro: FUNARTE; Fundação Teatro Municipal do Rio de Janeiro, 2001.

CHARTIER, Roger. À beira da falésia: a história entre certezas e inquietudes. Porto Alegre: Ed. Universidade/UFRGS, 2002a.

CHARTIER, Roger. A história cultural: entre práticas e representaçóes. - $2^{\mathrm{a}}$. ed. - Lisboa: Difel, 2002b.

CHARTIER, Roger. "Cultura popular': revisitando um conceito historiográfico". In: Estudos Históricos, Rio de Janeiro: Editora FGV, V. 8, nº 16, 1995.

CHAVES Jr., Edgar de Brito. Sessenta anos de história do Theatro Municipal. Rio de Janeiro: Ed. Americana, 1971.

COURBIN, Alain; COURTINE, Jean-Jacques; VIGARELLO, Georges (org.). História do Corpo. Petrópolis: Vozes, 2008, 3 volumes.

CORSEUIL, Jaques. "O futuro do Ballet Russo". Ilustraçáo Brasileira, p. 2829, maio 1942.

CORSEUIL, Jaques. "Paganini em pessoa”. Ilustraçáo Brasileira, p.10-11, mar 1943.

CORSEUIL, Jaques. "A volta do ballet russo". A cena muda, p. 8-9, 18 de abril de $1944 a$.

CORSEUIL, Jaques. "A dança ao lado das outras artes”. A cena muda, p. 8-9, 9 de maio de $1944 \mathrm{~b}$.

CORSEUIL, Jaques. Revista Vida, maio de 1944c, p. 48-49.

CORSEUIL, Jaques. "A temporada do Ballet Russo". Ilustraçáo Brasileira, p. 40, julho de 1944 d.

CORSEUIL, Jaques. “A temporada nacional de bailados”. Ilustraçáo Brasileira, p. 24, 25, 43, outubro, 1946.

CORSEUIL, Jaques. O Globo, p. 5, 26 de julho de 1946.

CRAINE, Debra; MACKRELL, Judith. Oxford dictionary of dance. Oxford, New York: Oxford University Press, 2000.

FARO, José Antonio. A dança no Brasil e seus construtores. Rio de Janeiro: Ministério da Cultura, Fundação Nacional de Artes Cênicas, 1988. 
GARAFOLA, Lynn. Legacies of twentieth century dance. Middletown: Wesleyan University Press, 2005.

GARAFOLA, Lynn. Diaghilev's Ballets Russes. New York: Da Capo Press, 1998.

GARCÍA-MÁRQUEZ, Vicente. The Ballets Russes: Colonel's de Basil's Ballets Russes de Monte Carlo 1932-1952. New York: Knopf, 1990.

GUARATO, Rafael. Seduzidos pelo passado: a crítica como fonte para história da dança. ARS (Sáo Paulo), [S. l.], v. 17, n. 37, p. 227-243, 2019.

GUINZBURG, Carlo. O fio e os rastros: verdadeiro, falso, fictício. São Paulo: Companhia das Letras, 2007.

HALBWACHS, Maurice. A memória coletiva. São Paulo: Centauro, 2006.

LOWENTHAL, David. "Como conhecemos o passado". In: Projeto História, n. 17. São Paulo: PUC-SP, p. 63-201, nov. 1998.

LAYSON, June. "Dance history and source material". In: CARTER, Alexandra. The Routledge dance studies reader. Londres, Nova York: Routledge, p. 144153, 1999.

LE GOFF, Jacques; TRUONG, Nicolas. Uma história do corpo na Idade Média. Rio de Janeiro: Civilizaçáo Brasileira, 2006.

LE GOFF, Jacques, CHARTIER, Roger, REVEL, Jacques (orgs.). A história nova. - 5a ed. - Sáo Paulo: Martins Fontes, 2005.

Le GOFF, Jacques. História e memória. - $4^{\mathrm{a}}$. ed. - Campinas: Ed. Unicamp, 1996.

MENESES, Ulpiano T. Bezerra de. "Os paradoxos da memória social”. In: Miranda, Danilo Santos de. (org.). Memória e cultura. A importância da memória na formação cultural humana. São Paulo: Ediçóes SESC/SP, 2007, p. 13-33.

MORRIS, Geraldine; NICHOLAS, Larraine. (ed). Rethinking dance history. London: Routledge, 2018.

NAVAS, Cássia; LAUNAY, Isabelle; ROCHELLE, Henrique. Dança, história, ensino e pesquisa: Brasil-França, ida e volta. Fortaleza: Indústria da Dança do Ceará, 2017. 
NORA, Pierre. "Entre memória e história: a problemática dos lugares". In: Projeto História - Revista do Programa de Estudos Pós-Graduados em História e do Departamento de História da PUC-SP, n.10, p.7-28, dez, 1993.

Original Ballet Russe, programa da temporada 1946-1947, realizada na cidade de Nova York e excursão 'costa a costa' nos Estados Unidos.

PAVLOVA, Adriana. Maria Olenewa: a sacerdotisa do ritmo. Série Memória 10. Rio de Janeiro: FUNARTE; Fundação Teatro Municipal do Rio de Janeiro, 2001.

PESAVENTO, Sandra J. História \& História Cultural. Belo Horizonte: Ed. Autêntica, 2003.

PEREIRA, Roberto. A formaçáo do balé brasileiro. Rio de Janeiro: Editora FGV, 2003.

PEREIRA, Roberto. Tatiana Leskova: nacionalidade: bailarina. Série Memória 6. Rio de Janeiro: FUNARTE; Fundação Teatro Municipal do Rio de Janeiro, 2001.

SANTOS, Milton. A urbanizaçáo brasileira. 5a edição. São Paulo: Edusp,2005.

SCHWARTZMAN, Simon; BOMENY, Helena, M. B.; COSTA, Vanda M. R (orgs.). Tempos de Capanema. São Paulo: Paz e Terra: FGV, 2000.

SUCENA, Eduardo. A dança teatral no Brasil. Rio de Janeiro: MinC/Fundacen, 1988.

VICTORICA, Vitoria Garcia. El Original Ballet Russe em America Latina. Buenos Aires: Guillermo Kraft, 1948.

WALKER, Kathrine Sorley. De Basil's Ballets Russes. New York: Atheneum, 1983.

Beatriz Cerbino é professora da Universidade Federal Fluminense, do curso de graduação de Produção Cultural, no departamento de Artes e Estudos Culturais, e no Programa de Pós-Graduação em Estudos Contemporâneos das Artes - PPGCA UFF. É pesquisadora do INCT Proprietas, colaboradora da Rede Iberoamericana de Videodança - REDIV, e pesquisadora colaboradora do Projeto TEPe - Technologically Expanded Performance.

ORCID: 0000-0001-9826-8352

E-mail: biacerbino@gmail.com 
Este texto inédito também se encontra publicado em inglês neste número do periódico.

Recebido em 30 de abril de 2021

Aprovado em 11 de agosto de 2021

Editores responsáveis: Arnaldo de Siqueira Junior Cassia Navas Henrique Rochelle Gilberto Icle

Este é um artigo de acesso aberto distribuído sob os termos de uma Licença Creative Commons Atribuição 4.0 Internacional. Disponível em: <http://creativecom mons.org/licenses/by/4.0>. 